Acknowledgement: This study was sponsored by Astellas Pharma, Inc. Medical writing support was provided by Rhian Harper Owen of Cello Health MedErgy and funded by Astellas Pharma, Inc

Disclosure of Interests: Daisuke Miyatake Employee of: Astellas Pharma, Inc., Tomohisa Shibata Employee of: Astellas Pharma, Inc., Mai Shibata Employee of: Astellas Pharma, Inc., Yuichiro Kaneko Employee of: Astellas Pharma, Inc., Kazuo Oda Employee of: Astellas Pharma, Inc., Tetsuya Nishimura Employee of: Astellas Pharma, Inc., Masataka Katashima Employee of: Astellas Pharma, Inc., Hisakuni Sekino Grant/research support from: Astellas Pharma, Inc., Kenichi Furihata Grant/research support from: Astellas Pharma, Inc., Akinori Urae Grant/research support from: Astellas Pharma, Inc.

DOI: 10.1136/annrheumdis-2019-eular.2413

\section{THU0183 UPADACITINIB PHARMACOKINETICS IN JAPANESE SUBJECTS WITH RHEUMATOID ARTHRITIS WITH THE EXTENDED-RELEASE FORMULATION AND COMPARABILITY TO NON-JAPANESE SUBJECTS}

Mohamed-Eslam Mohamed ${ }^{1}$, Ben Kluender2, Sebastian Meerwein ${ }^{2}$ Ahmed Othman ${ }^{1} .{ }^{1}$ AbbVie, North Chicago, United States of America; ${ }^{2}$ AbbVie Deutschland GmbH and Co. KG, Ludwigshafen, Germany

Background: Upadacitinib (UPA), an oral selective JAK1 inhibitor, is being developed for treatment of patients with moderate to severely active rheumatoid arthritis (RA). UPA efficacy was demonstrated in subjects with moderate to severe RA in five global Phase 3 studies and a regional Phase 2b/3 study in Japanese subjects.

Objectives: To characterize the pharmacokinetics of UPA after administration of the extended-release formulation in Japanese subjects with RA and to compare UPA plasma exposures between Japanese and non-Japanese subjects.

Methods: Population pharmacokinetic analyses were conducted using UPA data across Phase 1 to 3 studies including Japanese and non-Japanese subjects. The population pharmacokinetic model was used to estimate UPA plasma exposures from the extended-release formulation regimens in non-Japanese and Japanese subjects with RA in Phase 3 trials. Additionally, a total of 29 Japanese subjects with RA who were enrolled in SELECT-SUNRISE Phase $2 \mathrm{~b} / 3$ study participated in a pharmacokinetics substudy in which serial blood samples were collected from each subject over a 24 hour period after UPA dosing. UPA was administered in the study at doses of $7.5 \mathrm{mg}, 15 \mathrm{mg}$, and $30 \mathrm{mg}$ QD using the extendedrelease formulation. Pharmacokinetic parameters were calculated in the pharmacokinetic substudy using noncompartmental methods.

Results: UPA maximum plasma concentration was reached within 2 hours of dosing under fasting condition. UPA plasma exposures were approximately dose proportional over the evaluated dose range in Japanese subjects with RA. UPA model estimated plasma exposures (based on population pharmacokinetic analyses) were comparable (within 20\%) between Japanese and non-Japanese subjects with RA (Table 1). Results from the pharmacokinetic substudy using noncompartmental methods were consistent with the population pharmacokinetic analyses.

Abstract THU0183 - Table 1. Upadacitinib Model Estimated Exposures in Japanese and Non-Japanese Subjects with RA for the Extended-Release Formulation

\begin{tabular}{lcccc}
\hline & & \multicolumn{3}{c}{ Median $\left(\mathbf{5}^{\text {th }}, \mathbf{9 5 ^ { \text { th } }}\right.$ Percentiles $)$} \\
\hline Population & Treatment & $\mathrm{C}_{\max }(\mathbf{n g} / \mathbf{m L})$ & $\mathrm{C}_{\text {avg }}(\mathbf{n g} / \mathbf{m L})$ & $\mathrm{C}_{\text {trough }}(\mathbf{n g} / \mathbf{m L})$ \\
\hline Japanese & $7.5 \mathrm{mg} \mathrm{QD}$ & 24.0 & 8.8 & 2.4 \\
$(\mathrm{~N}=104)$ & & $(18.0,31.0)$ & $(5.0,15.2)$ & $(0.7,7.7)$ \\
Non- & $15 \mathrm{mg} \mathrm{QD}$ & 40.9 & 15.1 & 3.8 \\
Japanese & & $(28.2,54.7)$ & $(8.9,32.4)$ & $(1.3,21.3)$ \\
$(\mathrm{N}=1495)$ & & & & \\
Japanese & & 47.0 & 16.5 & 4.0 \\
$(\mathrm{~N}=97)$ & & $(36.7,70.2)$ & $(10.4,33.6)$ & $(1.3,22.2)$ \\
Non- & \multirow{2}{*}{$\mathrm{mg} \mathrm{QD}$} & 81.0 & 29.1 & 7.5 \\
Japanese & & $(57.2,113.9)$ & $(17.9,63.8)$ & $(2.4,40.5)$ \\
$(\mathrm{N}=850)$ & & & & \\
Japanese & & 97.7 & 35.1 & 9.5 \\
$(\mathrm{~N}=99)$ & & $(72.7,124.3)$ & $(21.7,59.7)$ & $(2.9,27.8)$ \\
\hline
\end{tabular}

Cmax: maximum plasma concentration; Cavg: average plasma concentration during a dosing interval; Ctrough: trough plasma concentration

Conclusion: No clinically relevant difference was observed in UPA plasma exposures between Japanese and non-Japanese subjects with RA.

\section{REFERENCES :}

[1] Mohamed, et al. Clin Pharmacol Drug Dev. 2018 Apr 24

[2] Genovese et al. Lancet. 2018;391(10139):2513-2524.

[3] Burmester et al. Lancet. 2018;391(10139):2503-2512.

Disclosure of Interests: Mohamed-Eslam Mohamed Shareholder of: AbbVie, Employee of: AbbVie, Ben Kluender Shareholder of: AbbVie, Employee of: AbbVie Deutschland $\mathrm{GmbH}$ \& Co. KG, Sebastian Meerwein Shareholder of: AbbVie, Employee of: AbbVie Deutschland $\mathrm{GmbH}$ \& Co. KG, Ahmed Othman Shareholder of: AbbVie, Employee of: AbbVie DOI: 10.1136/annrheumdis-2019-eular.605

\section{THU0184 SIROLIMUS SELECTIVELY INCREASES CIRCULATING TREG CELL NUMBERS AND RESTORES THE TH17/ TREG BALANCE IN RHEUMATOID ARTHRITIS PATIENTS WITH DAS28 $\leq 3.2$ WHO PREVIOUSLY RECEIVED CONVENTIONAL DMARDS}

Hong-Qing Niu ${ }^{1}$, LI Zhao-Hua ${ }^{1}$, Wen-Peng Zhao ${ }^{1}$, Xiang-Cong Zhao ${ }^{1}$, Chen Zhang ${ }^{1}$, Jing Luo ${ }^{1}$, Chong Gao ${ }^{2}$, Caihong Wang ${ }^{1}$, LI Xiao-Feng ${ }^{1} .{ }^{1} T h e$ Second Hospital of Shanxi Medical University, Department of Rheumatology, Taiyuan, China; ${ }^{2}$ Brigham and Women's Hospital, Harvard Medical School, Department of Pathology, Boston, United States of America

Background: Many immunosuppressants used to treat rheumatoid arthritis (RA) were designed to broadly suppress $T$ cell function, including that of regulatory $T$ cells (Tregs). Patients with inactive RA also show a reduced frequency of peripheral Tregs [1]. Tregs are essential for maintaining effective immune tolerance and a homeostatic balance of Th17/Treg. Accordingly, there has been increasing interest in developing Treg-friendly regimens to minimize or eliminate the immunosuppression of conventional medications for RA. mTOR signaling negatively controls the development and function of Tregs. Rapamycin, an mTOR inhibitor, could expand Tregs $\left(\mathrm{CD}^{+} \mathrm{CD}^{+} 5^{+} \mathrm{FoxP}^{+}\right)$in patients with active systemic lupus erythe matosus [2] and active RA [3]; however, the response of Tregs to rapamycin in RA patients with DAS28 $\leq 3.2$ is still unclear.

Objectives: To investigate the effects of rapamycin, under the generic name sirolimus, on Tregs in RA patients with DAS28 $\leq 3.2$ who previously received conventional DMARDs.

Methods: Fifty-five RA patients and 60 healthy controls were enrolled in this study. All patients had previously received conventional DMARDs and had a low DAS28 score $(\leq 3.2)$. Peripheral blood samples and clinical information were obtained at baseline and following 6 and 12 weeks of sirolimus treatment, or after 12 weeks of conventional treatment. The circulating levels of lymphocyte subpopulations were assessed by flow cytometry.

Results: Thirty-five patients received sirolimus and 20 patients continued treatment with conventional DMARDs. None of the baseline clinical char acteristics differed significantly between the two groups. The absolute counts and proportions of $\mathrm{CD}^{+} \mathrm{CD} 25^{+} \mathrm{FoxP} 3^{+}$Tregs were significantly lower in all RA patients with DAS28 $\leq 3.2$ as compared with those in healthy controls. By contrast, the difference in circulating Th17 cell numbers was not significant. Sirolimus administration resulted in significant elevations in circulating Treg cell numbers and significant reductions in the Th17/Treg cell ratio, whereas the circulating level of Tregs and the Th17/Treg cell ratio in patients under conventional treatment both showed a tendency of reduction (Figure 1). Furthermore, a greater proportion of patients under sirolimus treatment achieved DAS28-based remission at 12 weeks.

Conclusion: Sirolimus can favorably expand Tregs in RA patients with DAS28 $\leq 3.2$, consequently restoring a healthy balance of Th17/Treg cells, which might improve the likelihood of long-term and sustained clinical remission and reduce the probability of disease flare-ups in RA. These findings provide valuable insights that might potentially lead to changes in clinical practice for the routine treatment of RA.

\section{REFERENCES :}

[1] Niu Q, Cai B, Huang ZC, Shi YY, Wang LL. Disturbed Th17/Treg balance in patients with rheumatoid arthritis. Rheumatol Int, 2012, 32(9): 2731 2736 .

[2] Lai ZW, Kelly R, Winans T, et al. Sirolimus in patients with clinically active systemic lupus erythematosus resistant to, or intolerant of, conventional medications: a single-arm, open-label, phase 1/2 trial. Lancet, 2018, 391 (10126): 1186-1196

[3] Wang J, Zhang SX, Hu FY, et al. Sirolimus treatment in patients with refractory rheumatoid arthritis: a double-arm, open-label, phase 1/2 trial. 